\title{
Several Factors Hindering the Cultivation of Legal Belief in Contemporary China*
}

\author{
Xuguang Liu \\ School of Marxism \\ Shanghai University of Political Science and Law \\ Shanghai, China 201701
}

\begin{abstract}
As the spiritual implication of socialist rule of law with Chinese characteristics, legal belief is an important value support for the construction of the rule of law in China. However, the cultivation of legal beliefs carried out nowadays is hindered by many factors, which in turn affects the belief of the whole society in law. Wherein, the deviation of citizens' cognition on law, the problems existing in the operation process of current laws, the citizens' obligation-based consciousness under the influence of the "rule of man" in traditional Chinese society, and the national psychological habits against the background of human relationship society all bring challenges to the cultivation of contemporary Chinese legal beliefs. Therefore, having a deep understanding of several factors that hinder the cultivation of contemporary Chinese legal beliefs has important theoretical value in cultivating and guiding citizens to have a sincere belief in law.
\end{abstract}

Keywords—socialist rule of law; legal belief; rule of man; obligation-based consciousness

\section{INTRODUCTION}

Legal belief is an intrinsic open and autonomous legal system of human body in terms of fairness, justice, freedom, order, and the like essences, and is the attitude of awe, acceptance, recognition, obedience and adherence after undergoing a theoretical cognition and emotional experience. In the context of contemporary China, governing the country according to law has become China's strategy of constructing a socialist modern state with characteristics. The shaping of legal culture centered on legal belief is an important dimension of the construction of the rule of law in China in the new era. Making a deep analysis and research on the factors affecting the cultivation of contemporary Chinese legal beliefs is of very vital theoretical meaning and practical value.

*Fund: This paper is a phased research result of the Shanghai Higher Education Society Planning Fund Project hosted by Xuguang Liu: "Research on Boosting Xi Jinping's 'Three Accesses (Incorporating into textbook, bringing into classroom and entering into students' mind)" Thoughts of Socialism with Chinese Characteristics in the New Era by Means of New Media Micro-course: Taking the Course of 'Ideological and Moral Cultivation and the Basis of Law' as an Example (Project No. GJEL1870)".

\section{Legal Cognition AND PROBLEMS Existing IN THE OPERATION PROCESS OF LAW}

\section{A. Legal Cognition of the Instrumental View of Law}

The existence of legal instrumentalism leads to such a social and cultural atmosphere as quite distrustful to law, and cools down the hot legal feelings of the public. The so-called legal instrumentalism means that law is a thing that has no independent value and goal. Once other instruments are found to be able to maximize the utility of social control in a short term, the law can be quickly replaced or displaced; so, the instrumental view of law is easy to produce legal nihilism. The idea that legal instrumentalism implies a power superior to the law weakens people's trust and belief in law.

\section{B. Problems Existing in the Process of Formulation and Implementation of Laws}

Since the new era, with the standardization of legislative work and the deepening development of the rule of law, China's legislative cause has had a clear legal basis, and the formulation of laws has gradually become rational and perfect. However, due to the expansion of legislation and the problems existing in the procedures of law promulgation, it is easy to lead to the dilemma that the laws enacted by the state cannot meet the needs of the public. Consequently, citizens may have a sense of distance and strangeness on law, which may further make the legal beliefs of contemporary China impossible to produce. In the operation process of law, especially in the judicial field, there are also many problems to be resolved urgently. The trial independence of the court is the practical requirement of the concept of socialist rule of law with Chinese characteristics. The real life of law lies in its implementation. Only if a law has independent judicial trial right can it win the public's belief. The life of law should be measured by its operation; otherwise it is just like a worthless piece of paper and thus is not as good as having no the law. The specific operation status of the law determines the actual effect of the law implemented in practice. Specifically, the operation of law is the implementation of law; hence a strict law enforcement and fair justice is required to ensure the good operation of law. This is also an important condition for improving people's legal awareness and cultivating people's belief in the law. 
political powers. 1 The practice in traditional Chinese history also proves that people have subtly fully accepted the concept of "rule by man" in which "power is superior to law" and law is only a powerful tool for punishing crime and maintaining the rule. The occurrence of this phenomenon is inseparable from the environmental impacts of "acquaintance society" and "relationship society" in the same village and community where people live. Especially in the vast rural areas, some national administrative officials in the grass-roots level cannot form a correct recognition on law due to the deep influence of power-oriented thought and the thought of rule by man in addition to their poor law consciousness. All in all, the "thought of rule by man" still restricts people's attitude towards the value of law to a certain extent, and further affects and hinders citizens' belief in law.

2) Misplacement of the concept of rights and obligations. Although the obligation-oriented thinking has been gradually questioned by citizens under the subtle influence of legal consciousness in modern society, this thinking still have subtle impact on citizens' consciousness in rural areas that are relatively backward from the development in urban areas. When facing damage to their rights, most peasants are accustomed to blind forbearance and obedience, and cannot actively and positively seek legal approaches to solve problems, which inevitably leads them to evade legal approaches. Consequently in real life, citizens have weak consciousness to maintain their rights, let alone their belief in law. In the practice of specific social life, the misplacement of rights and obligations is even a serious imbalance and is precisely the concentrated reflection of the "obligationoriented" legal concept. Against such traditional cultural background, abiding by the law is a common behavioral requirement for people, and it is also a concentrated reflection of negative obedience. In the long run, people may not know what their rights are, and even do not know that once their rights are infringed, they should take legal weapons to protect themselves. This phenomenon is particularly prominent in rural areas in the context of contemporary China. Under the influence of obligationoriented thinking, even if everyone obeys the law, obedience and obligation are still highlighted practically, and finally evolve to evading and questioning the law, let alone belief in law.

\section{B. National Mentality in the Traditional Human Relationship Society}

In traditional Chinese legal concept, it is often said that "law is generally not beyond human feelings" which means that law must reflect human feelings. Moreover, Chinese people often mention human feelings in the same breath as the principle of heaven and the law of the land. Professor Fan control mode formed by the multi-equal interest groups in the society or the mutual control and restriction between

[United States] Scott Gordon. (trans.)Ying Qi. Controlling the State - Constitutionalism from Ancient Athens to Today [M]. Nanjing: Jiangsu People's Publishing Ltd., 2001: 17. 
Zhongxin believes that "in the eyes of traditional Chinese people, the principle of heaven, the law of the land and human feelings are not only connected, but can even be understood as the 'three in one'. The core of the three concepts is the the law of the land which is the only rule that is material and can be seen and directly accepted. The other two have no material form. "2

In the actual social activities of Chinese people and in the process of interpersonal communication, human feeling as a behavioral norm of dealing with people is very crucial. That is to say, in the eyes of the Chinese, "conforming to human feelings" is most important, followed by "conforming to the principle of heaven" and then the "conforming to the law of the land". Therefore, in traditional Chinese culture, it is difficult to imagine the concept of "legal supremacy." Because in traditional Chinese culture, more attention is paid to the relationship between people, namely the natural blood relationship between people. Under the influence of such cultural concept, the "family and country integrated" ethical society and country was established and formed. In traditional Chinese culture, emotive reason is highlighted more than legal principle. Although in theory, the law surely should be in line with human feelings or emotive reasons as much as possible and try to achieve the unity of feeling, reason and law. It is even said that the compliance with emotive reason should be incorporated into legal norms and be included in the legal system. In addition, the human sentiment culture in traditional society particularly emphasizes harmony and common prosperity; reflected in the legal design, it attaches importance to obedience and obligation so that people have no sense of litigation. In the sense of the times, it is more in line with the reality of traditional Chinese society, and is easy to be mentally accepted by Chinese people, which led to the development of mediation system in ancient Chinese legal culture. The mediation system is very important for easing social conflicts, reducing social costs, eliminating the phenomenon of litigation abuse, and reaching overall harmony of the society. It is a valuable asset that China contributes to the entire human race. The concept of harmony and non-lawsuit is rational, but it also poses negative influences such as ignoring the rule of law, lowering the status of law, and the proliferation of the thought of rule by man. Therefore, the national psychology in the traditional human relationship society tends to lead people to despise the law, pay attention to the human ethics in subjective judgment choices; it is easy for the state or society to have negative attitudes towards the law, and even treat the law as a shameful thing. This phenomenon has directly hampered the cultivation of contemporary Chinese legal beliefs.

\section{REFLECTIONS ON THE CULTIVATION OF LEGAL} BELIEF IN THE DUAL CONTEXTS OF CONTEMPORARY CHINA

The establishment of legal beliefs has dual contextual influences in contemporary China, namely the economic logic of the socialist market economy with Chinese

Fan Zhongxin, Zheng Ding, Zhan Xuenong. The Passion, Sense and Law of Chinese People (Revised Edition) [M]. Beijing: Peking University Press, 2011:23. (in Chinese) characteristics and the burden under the influence of traditional Chinese culture. In contemporary China, the real society is a society of socialist market economy. The logic of the market is to maximize profits. This motivation for merely making profit leads to human materialization and extreme individualism, and has caused serious social crisis. However, the crisis is often accompanied with salvation, and the socialist market economy itself offers a new possibility of rules and values. It is necessary to play the positive role of market economy and try to eliminate its negative side by virtue of the rule of law and legal beliefs. The active subject's active adaptation to reality based on their ideal is their active self-remolding. New social order and new belief and concept are generated with the subject's continuous pursuit for and exploration on self-belief and social order and value. It is believed that the belief in law is a new belief concept generated especially in the field of law under the social conditions of socialist market economy with Chinese characteristics. In the context of contemporary China, specific problems existing in the operation course of law are recognized and improved by taking applicable measures. So, under the influence of the establishment of the rule of law in socialism with Chinese characteristics and the concept of legal culture, legal belief must have its own, important and necessary position.

The establishment of a socialist rule of law society with Chinese characteristics has always been facing the problem of how to treat traditional culture. The development from tradition to the present is essentially a huge transformation in social structure. Fundamentally, the legal order and legal belief pursued nowadays are heterogeneous with tradition. The contemporary society emphasizes revealing the law on rights of the subjects. In contrast, the ancient Chinese society is a typical patriarchal society where "rule by man" is the core, ritual is the basic norm for social order; this value and concept has been internalized in the mind of Chinese people and still exists even over thousands of years. Therefore, it is inevitable to rebuild traditional culture, replace the traditional backward thinking with new beliefs, replace the rule by man with the rule of law, and replace the traditional distorted personality and the mentality of small farmers with the free personality, freedom consciousness and equality spirit of citizens. It is not wise to be driven by the wheel of history and society but conform to the situation, hold a correct critical attitude towards the past, and actively reconstruct new national consciousness and social spirit. In this process, both the rule of law and legal belief will play a key and irreplaceable role.

\section{CONCLUSION}

To sum up, it is necessary to focus on the theoretical innovation and practice introspection on China's rule of law in the new era, analyze and know about the factors hindering the cultivation of legal belief in contemporary China; the main focus is that it is a must to abandon the cognition of legal instrumentalism, in addition to critically inherit the essence of traditional legal culture. In general, from a practical point of view, the problems existing in the process of specific operation of the law in the context of contemporary China make people doubt the law, and even 
reject and resent the law, let alone belief in law; from the cultural, traditional and other aspects, the national psychological inertia of Chinese traditional culture and the bias of cognition on the nature of law under the influence of traditional culture and the like all have affected the cultivation of contemporary Chinese legal beliefs to varying extents.

\section{REFERENCES}

[1] [United States] Scott Gordon. (trans.)Ying Qi. Controlling the State - Constitutionalism from Ancient Athens to Today [M]. Nanjing: Jiangsu People's Publishing Ltd., 2001: 17.

[2] Fan Zhongxin, Zheng Ding, Zhan Xuenong. The Passion, Sense and Law of Chinese People (Revised Edition) [M]. Beijing: Peking University Press, 2011:23. (in Chinese)

[3] [United States] Berman. (trans.) Liang Zhiping. Law and Religion [M]. Beijing: China University of political science and Law Press, 2003.

[4] [United States] Berman. (trans.) Yao Jianbo. Faith and order: the combination of law and Religion [M]. Beijing: Central Compilation and Translation Press, 2011. 